\title{
FABRICATION OF THE PROTOTYPE 201.25 MHZ CAVITY FOR A MUON IONIZATION COOLING EXPERIMENT*
}

\author{
R.A. Rimmer, S. Manning, R. Manus, L. Phillips, M. Stirbet, K. Worland, G. Wu, JLab, \\ D. Li, R. MacGill, J. Staples, S. Virostek, M. Zisman, LBNL, \\ K. Taminger, R. Hafley, R. Martin, NASA Langley, \\ D. Summers, M. Reep, Univ. Mississippi.
}

\begin{abstract}
We describe the fabrication and assembly of the first prototype $201.25 \mathrm{MHz}$ copper cavity for the muon ionization cooling experiment (MICE). This cavity was developed by the US MUCOOL collaboration and will be tested in the new MUCOOL Test Area at Fermilab. We outline the component and subassembly fabrication steps and the various metal forming and joining methods used to produce the final cavity shape. These include spinning, brazing, TIG welding, electron beam welding, electron beam annealing and deep drawing. Some of the methods developed for this cavity are novel and offer significant cost savings over conventional construction methods.
\end{abstract}

\section{INTRODUCTION}

This cavity has been developed by the US Neutrino Factory and Muon Collider Collaboration (MC), which is working towards demonstrating the key technologies needed for a neutrino factory and ultimately a muon collider [1]. The high-gradient (16 MV/m) $201.25 \mathrm{MHz}$ cavity [2], is needed to provide re-acceleration in the ionization cooling channel and must operate in a multiTesla magnetic field so it cannot be superconducting. The low frequency is necessary to accommodate the dilute phase space of the beam. Demonstration of this type of cavity at high gradient in a strong magnetic field is a key milestone towards establishing the feasibility of a neutrino factory as a realistic choice for a near-term facility. This design will be tested soon in the new MUCOOL Test Area (MTA) at Fermilab and will form the basis of the RF section for the MICE experiment at RAL [3].

\section{FABRICATION}

The construction of this cavity has been a collaborative effort between JLab (fabrication and assembly), LBNL (fabrication, engineering and design), NASA Langley (ebeam welding) and the University of Mississippi (fabrication), and was funded by DOE through the MC.

\section{Half-shells}

The cavity body is made from two half-shells, figure 1, that were fabricated by an outside vendor in Minnesota by the spinning technique. Dimensional tolerances were held well but there was some degradation of the material surface on the inside.

*This work was supported by SURA, Inc. under Contract No. DEAC05-84ER-40150 with the U.S. Department of Energy, by LBNL under contract DE-AC03-76SF00098, and by NASA contract IA1-533 subagreement \#2.

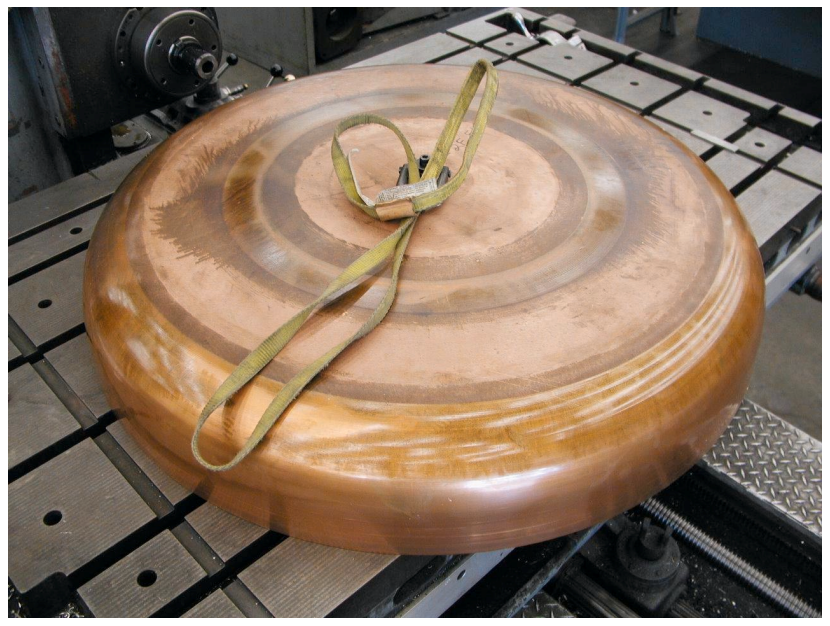

Figure 1: Spun cavity half-shell.

\section{Tuner ring}

Each half-shell has a strong tuner ring is attached by ebeam welding before the cavity is joined together. This ring is eventually the mounting point for the tuner but, during fabrication, it is used for fixturing and handling the cavity. The ring is positioned by a "spider" located by a dowel pin in the central hole in the half-shell, see figure 2. The ring is tack-welded to the shell and then the spider is removed and the ring is welded all the way around on both the ID and OD. After welding the ring is trimmed true to the OD of the shell and parallel to the equator. Once the half-shells are welded together these become the datum surfaces.

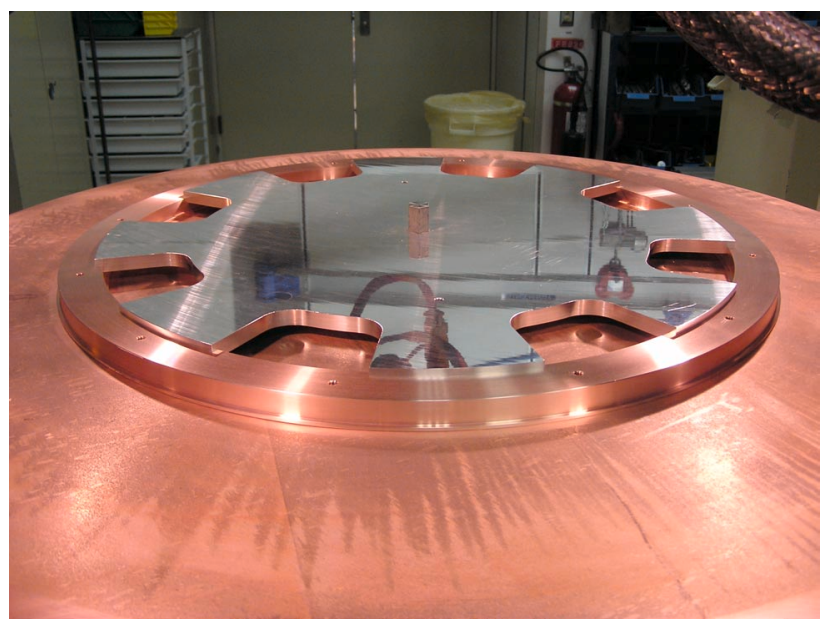

Figure 2. Tuner ring ready for e-beam welding. 


\section{Beam-iris opening}

After the tuner rings are welded in place and the edges trued, the center of the shell is cut out and the weld joint prepared for receiving the "nose ring" (so called because it is the part that would have the nose-cones in a conventional cavity even though there are none in this case). While the shells are in the machine shop the weld preps for the equator joint are also cut.

\section{Equator weld}

The equator weld is done in two parts, a full penetration weld from the outside, figure 3 , and a cosmetic pass on the inside, figure 4 , to leave a smooth surface. The two half-shells are clamped together in a fixture that captures the tuner rings and is rotated by a chain and sprockets from the welder rotary table. For the inside weld, the now one-piece cavity is placed horizontally on the turntable and the gun angled to see the inside of the joint through the beam iris. Both of these set-ups were a tight fit in the JLab e-beam welder.

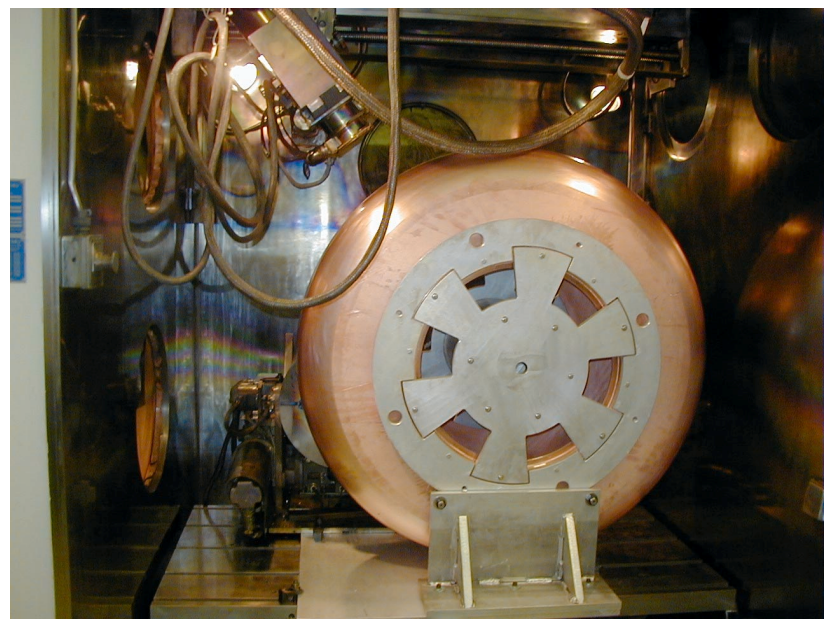

Figure 3. Outer equator weld in the JLab e-beam welder.

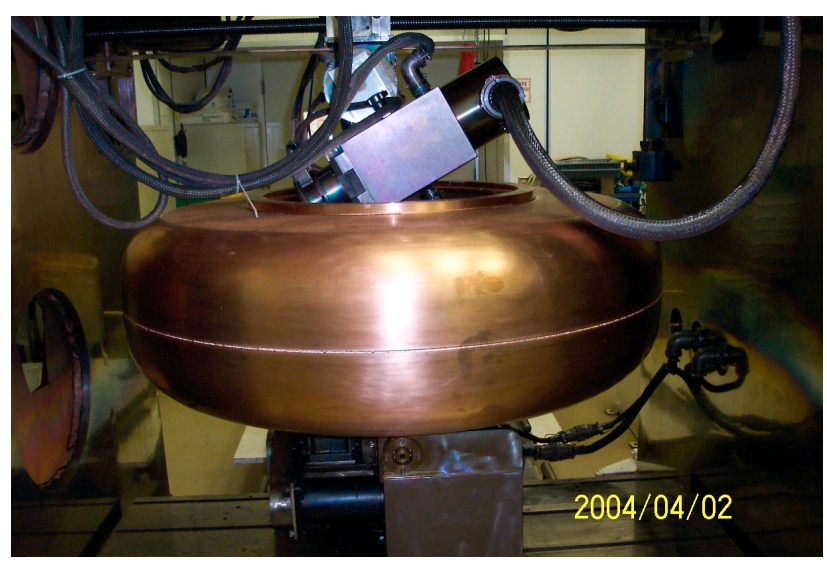

Figure 4. Inside cosmetic weld in the JLab e-beam welder.

\section{Nose welding}

The next major welding operation was the joining of the nose rings into the cavity. This was also a two-sided weld with a penetration weld from the outside followed by cosmetic welds on both sides, figure 5 . Due to schedule conflicts and space concerns, this part of the assembly was performed at nearby NASA Langley, where there is a similar but larger Sciaky welder. We were fortunate that the welder was available and the experienced operators were quickly up to speed on the requirements for this project. We developed beam weld parameters for the cosmetic and penetration welds and performed the nose welds with excellent results.

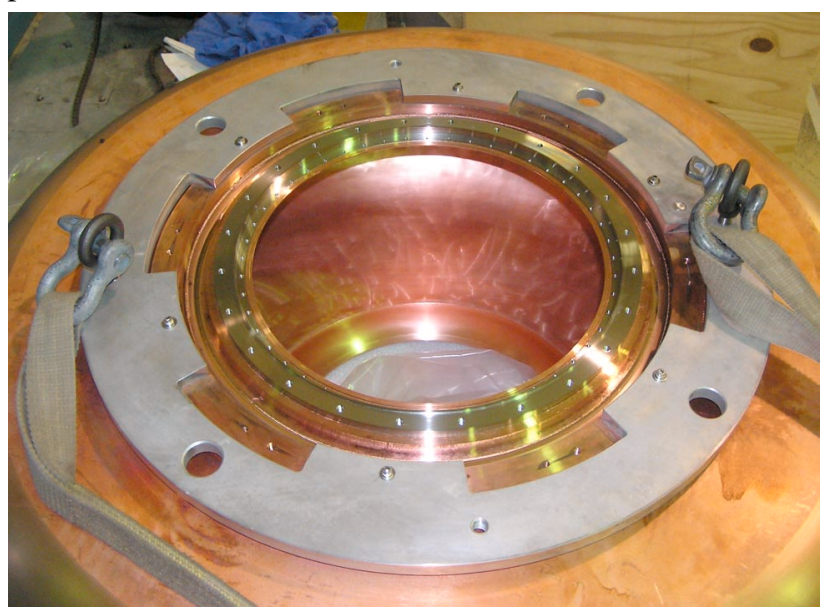

Figure 5. "Nose" insert welding done at NASA Langley.

\section{Equatorial ports}

The original design called for the four equatorial ports to be pre-fabricated and e-beam welded into the body. Pulling the ports directly out of the cavity body would be simpler, but we expected the material to tear in the heataffected zone of the equator weld (as indeed it did in test samples). Locally annealing the region around the port with the e-beam welder permitted us to pull the ports directly, figure 6 , saving considerable time and cost over the original method.

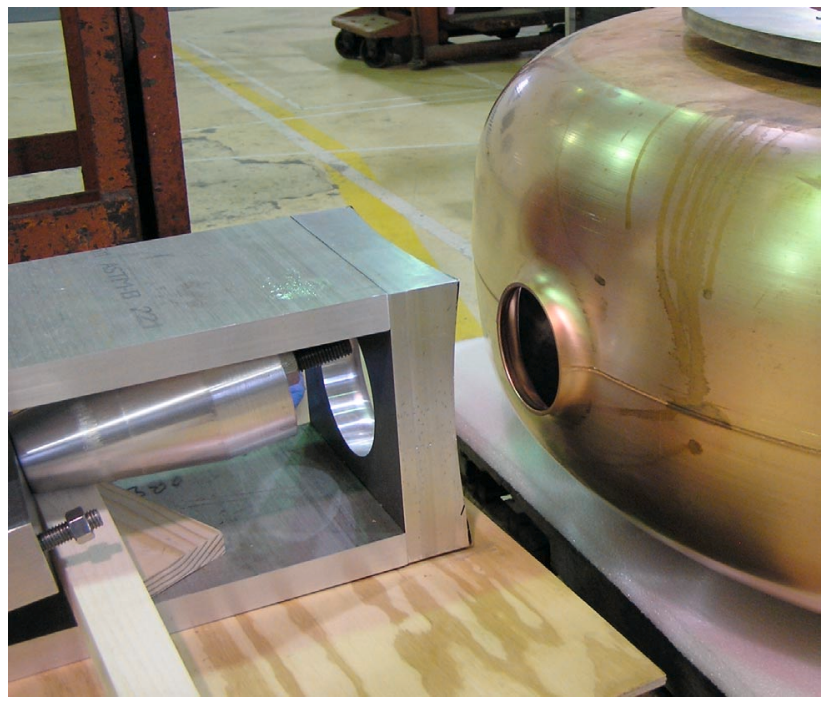

Figure 6. Port pulling after e-beam annealing.

\section{Port flange welding}

The port flanges are commercial 6.75" Conflat flanges in stainless steel. These have copper inserts brazed in and 
are joined to the cavity by a copper to copper e-beam weld. This operation requires rotating the cavity rapidly about the port axis, and performing a penetration weld followed by a cosmetic weld, both from the inside. The first weld over-penetrated somewhat and failed to smooth over completely on the cosmetic pass. Turning the beam power down on subsequent ports resulted in no further problems. Unfortunately the blow through on the first port created a leak that proved very resistant to repair.

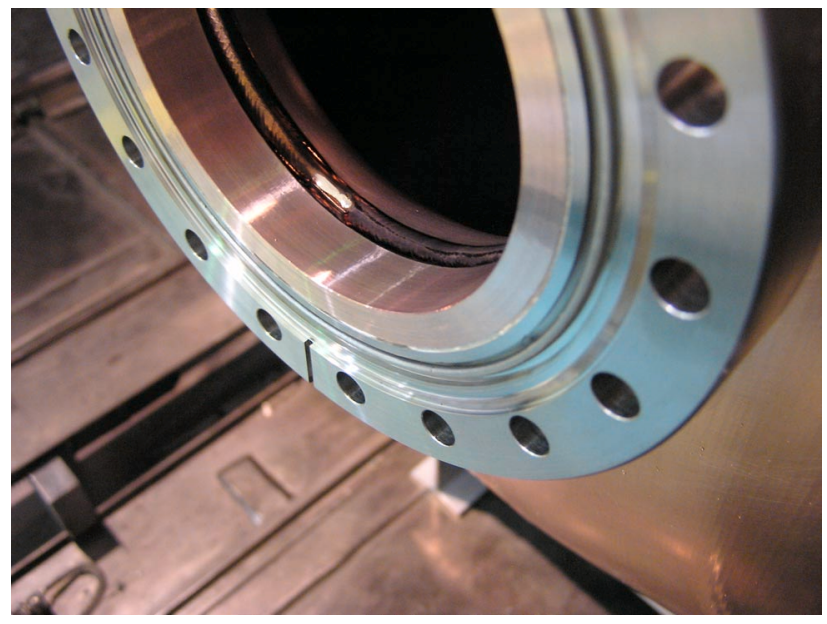

Figure 7. Port flange e-beam welded to cavity.

\section{Port repair}

Attempts to seal the leak in the flange joint by TIG welding and TIG brazing were ultimately unsuccessful. Eventually the damaged port was cut out and a new one welded in following the original port assembly plan. A new port was fabricated by the same extrusion method and joined to a new flange. A step joint was prepared on the cavity body and the outer edge of the port. Using TIG welding the joint was stitch welded on the outside for strength and fully sealed on the inside.

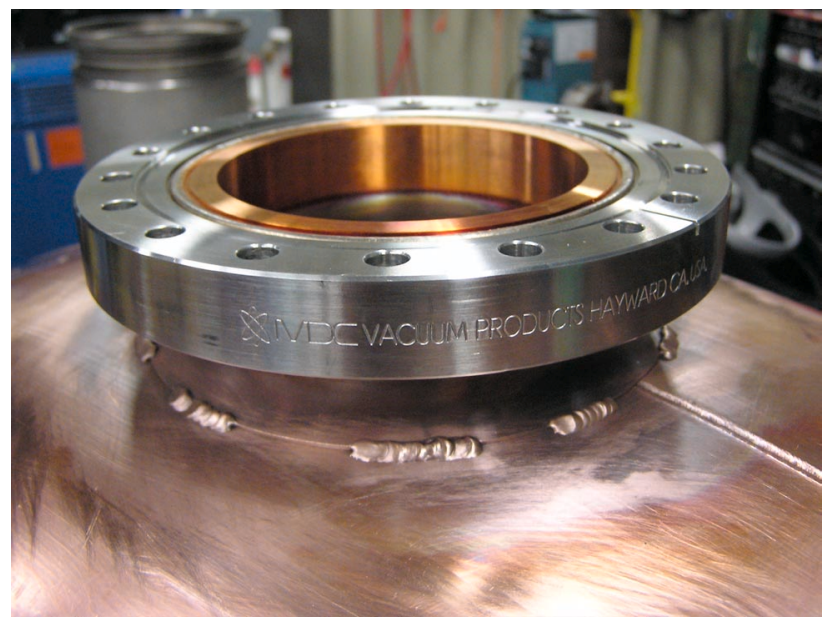

Figure 8 . Port repaired by TIG welding.

\section{Cooling channels}

The average power dissipation in this cavity is less than $10 \mathrm{~kW}$ so simple cooling tubes can be used on the outside of the body, TIG brazed using silicon-bronze alloy in a "stitch" pattern, see figure 9. This provides sufficient thermal contact while reducing the time and materials and also avoids trapped volumes under the braze joint. (For MICE the cavity will be inside an evacuated chamber.)

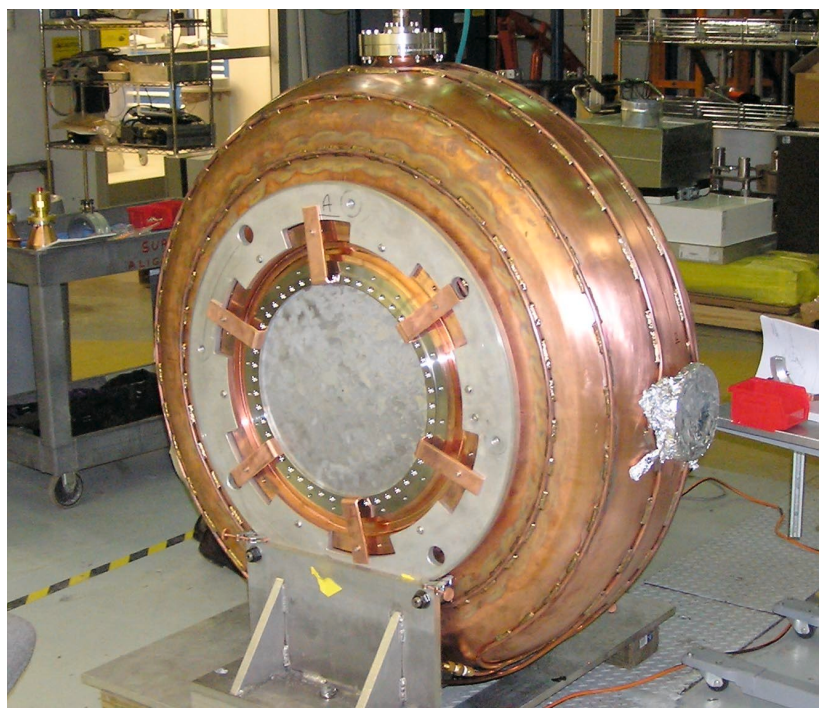

Figure 9. Cooling tubes TIG brazed with "stitch" pattern.

\section{Final cleaning}

Heavy field emission could be a serious problem for the liquid hydrogen absorbers or instrumentation in MICE. For this reason it was decided to electro-polish the highfield surfaces of the cavity. Mechanical polishing followed by light chemical cleaning will precede the electro-polish. Final preparation will include highpressure rinsing and vacuum assembly in a cleanroom.

\section{High-power testing}

The cavity will be tested in the MTA at FNAL using a pair of loop couplers with SNS style coaxial windows from Toshiba Corp.

\section{CONCLUSIONS}

Despite schedule conflicts and a few technical problems, the cavity has finally been completed and will shortly be delivered to FNAL for testing in the MTA. We are eager to see how it performs in the harsh environment for which it is destined. We would like to thank our many colleagues who have contributed to this project and especially Toshiba Corp for generously donating the windows when our original source fell through.

\section{REFERENCES}

[1] "Recent progress in neutrino factory and muon collider research within the Muon Collaboration“" PRST-AB,VOL 6, 081001 (2003).

[2] D. Li et. al., “A $201 \mathrm{MHz}$ RF Cavity Design With Non-Stressed Pre-Curved Be Windows For Muon Cooling Channels", EPAC 2004, Lucerne.

[3] P. Drumm, "MICE: The International Muon Ionisation Cooling Experiment", these proceedings. 